\title{
Toxicity of Randia nilotica fruit extract on Schistosoma mansoni, Biomphalaria pfeifferi and Bulinus truncatus
}

\author{
ALADDIN YOUSIF ELTEIB EBODI, MOHAMMED MAGZOUB AHMED \\ Department of Parasitology, Faculty of Veterinary Medicine, University of Khartoum. Al-Gamaa Av., Khartoum, Sudan, `email: dc.itna@uofk.edu
}

Manuscript received: 14 April 2017. Revision accepted: 21 June 2017

\begin{abstract}
Ebodi AYE, Ahmed MM. 2017. Toxicity of Randia nilotica fruit extract on Schistosoma mansoni, Biomphalaria pfeifferi and Bulinus truncatus. Cell Biol Dev 1 (1): 23-30. The aqueous filtered and unfiltered extract of the fruits of Randia nilotica (locally named Shagarat El-Murfaein) were assessed as molluscicides against Biomphalaria pfeifferi and Bulinus truncatus, as well as their effect on cercariae and miracidia of Schistosoma mansoni. The plant was tested on uninfected B. pfeifferi and B. truncatus, and the results showed that unfiltered extracts were found to be relatively more potent than filtered ones (i.e., $100 \%$ was attained at $90 \mathrm{ppm}$ and $80 \mathrm{ppm}$ ), respectively. The filtered extract was tested on uninfected B. pfeifferi and B. truncatus (100\% was attained at $100 \mathrm{ppm}$ and $90 \mathrm{ppm}$ ), respectively. The effect of the unfiltered extract on infected B. pfeifferi produced $100 \%$ mortality in a concentration of $70 \mathrm{ppm}$. The activity of the plant on cercariae and miracidia revealed that cercariae were more resistant than miracidia (i.e.50 ppm killed all cercariae within 3 hours while killed miracidia within 2 hours. The results were statistically analyzed and discussed, and the findings were promising and could open new avenues for the practical use of the plant in the field.
\end{abstract}

Keywords: Toxicity, Randia nilotica, fruit extract, Schistosoma mansoni, Biomphalaria pfeifferi, Bulinus truncatus

\section{INTRODUCTION}

Schistosomes are digenetic trematodes that belong to the family Schistosomatidae. They inhabit the blood vessels of their hosts and are therefore known as blood flukes. Schistosomiasis (bilharziasis) is an important public health issue for rural communities near and around slowmoving water bodies in the tropics and subtropics. It is estimated that over 200 million people in 73 countries are infected (McCullough and Mott 1983), while a further 500600 million or $4-5 \%$ of the world's population are at risk of being infected (Basch 1991; Brown 1994). Africa, China, and the new tropics are the most extensively infected areas. Man participated in the spread of schistosomiasis by creating habitats suitable for the snail hosts and the dispersal of the parasites through the traveling of infected people (Brown 1994).

In Africa, schistosomiasis is found in most countries, and the number of infected persons was estimated to be 90 million, while 180 million persons are at risk (Korte and Mott, 1980; Inobaya et al., 2014). There are five major species of schistosomes affecting humans. These species differ not only biologically but also in their geographical distribution and the types of infection they produce. Intestinal schistosomiasis, caused by Schistosoma mansoni, occurs in Africa, Eastern Mediterranean, Caribbean Islands, and South America. S. japonicum, also known as Asian schistosome, is present in southeast Asia, China, and the Philippines and only in small foci in other countries (Wains and McManus 1997). Another form of intestinal schistosomiasis, caused by $S$. intercalatum, has been reported in Africa in parts of Cameroon, Gabon, and northeast Zaire (Doumenge et al., 1987; Lai et al., 2015).
Finally, urinary schistosomiasis is caused by $S$. haematobium, which occurs in Africa and Eastern Mediterranean.

In Sudan, the history of schistosomiasis began after the building of the Sennar Dam in 1925 and the establishment of the Gezira Agriculture Scheme. As a result, integrated schistosomiasis control programs were recommended by the World Health Organization (WHO) in 1994. Snail control is an important preventive strategy for treating infected people, together with environmental and socioeconomic improvements, health education, and community participation. Although chemical molluscicides are the most used approach to snail control (WHO 1973, 1994), chemicals have their hazards. In addition to their high costs, they may be toxic to aquatic fauna and a source of pollution. All factors make it imperative to consider using naturally growing or locally cultivated molluscicides of plant origin.

This study is intended to determine the efficiency of the plant Randia nilotica on the adult snail hosts, on cercaria, and the miracidia of Schistosoma mansoni.

\section{MATERIALS AND METHODS}

\section{The plant}

Randia nilotica is a plant that belongs to the family Rubiaceae. The plant is locally known as Shagarat ElMurfaein. The fruits of this plant are the parts used in this study. It was collected from the Kordofan area in Western Sudan. Plant Extraction was performed at the Department of Pathology, Faculty of Veterinary Medicine, University 
of Khartoum. In the laboratory, the fruit was air dried under shade before they were coarsely powdered.

\section{The snails}

\section{Snail collections}

The snails used throughout the experiments were Biomphalaria pfeifferi and Bulinus truncatus, which are the most important vectors for the transmission of human and animal schistosomiasis in Sudan (Hussein 1973; Sulaiman and Ibrahim 1985; Jordan et al. 1993), as well as subSahara Africa (Hotez and Fenwick 2009; Hotez and Kamath 2009; Steinmann et al. 2006). Deep scooping collected the snails from the El-Seleit irrigated area on the Eastern part of the Blue Nile. The scoops were constructed from the kitchen sieves, supported by an iron frame, and mounted on a handle (1-2 meters long). The snails were then maintained and bred in the laboratory of bilharziasis at the Department of Pathology, Faculty of Veterinary Medicine, University of Khartoum.

\section{Snail breeding}

About 10-20 snails were put in plastic tanks, in which the water was changed even three days by normal dechlorinated water and was cleaned periodically from faecal debris. The temperature in the laboratory was kept at $25-30^{\circ} \mathrm{C}$. The snails were fed dried lettuce leaves, prepared as follows, by washing green leaves of lettuce with boiling water, and allowed to dry. The water used for snail breeding was tested using a flame spectrophotometer to determine its chemical composition. The same water was then used to determine the laboratory's rate of development and hatching these snails. The egg masses produced by these snails were deposited on small pieces of cellophane materials, which were placed on the top surface of the water in the tanks to collect eggs. The cellophane materials contaminated with egg masses were removed daily and placed on water in other tanks to maintain the hatching of eggs and the growth of embryos. Finally, the juvenile snails were fed on algae or dried lettuce, and the range of growth and hatching periods were observed.

\section{Extract preparation}

The method of extract preparation described by Brackenbury et al. 1997) and Brackenbury (1999) was adopted in the experiment. The sum of 2.5 grams of coarsely powdered materials of $R$. nilotica fruits was soaked in $200 \mathrm{ml}$ of distilled water in a flask for 24 hours. The contents of the flask were then filtered, and the volume was adjusted up to $250 \mathrm{ml}$ using distilled water. A stock solution was then prepared for future use.

\section{Test for molluscicidal activity}

The test procedure, which was applied to the materials obtained from the fruits of $R$. nilotica, was carried out according to the method recommended by WHO (1965). Ten viable snails were put in one liter of the extract concentration and left for another 24 hours. They were then removed and put in dechlorinated water for another 24 hours as a recovery period. First, the number of dead snails was recorded. Then, the control was prepared by putting another group of ten snails in one liter of dechlorinated water devoid of the extract. The snails are usually considered dead when they show a lack of movements, retraction, or hanging out of their shells; in such cases, the snail bodies and shells will be discolored. Death is also confirmed by a lack the reaction to any external stimulus from the surrounding water. Therefore, the numbers of dead and living snails were recorded after 24 hours of exposure, followed by 24 hours of a recovery period.

\section{The molluscicidal activity of Randia nilotica on Biomphalaria pfeifferi and Bulinus truncatus}

Different dilutions were prepared from the stock solution prepared from $\mathrm{R}$. nilotica fruits to study their molluscicidal activity on $B$. pfeifferi and B. truncatus. A group of ten viable $B$. pfeifferi and another group of ten $B$. truncatus snails each were put in one liter of the extract solution of known concentration in a container and exposed for 24 hours. First, titration was used at the rate of 100 , 200, 300, 400, 500, and $600 \mathrm{ppm}$. According to the results obtained from the titration, different other concentrations were used for further screening to achieve mortality percentages ranging from zero to $100 \%$; the experiment was repeated three times, and the average obtained from the three readings was taken. Control results were similarly taken. Two types of extract were used, the first one the filtered extract and the other unfiltered. The extract was used against uninfected Bulinus, infected and uninfected Biomphalaria

\section{Miracidicidal activity test}

\section{Production of miracidia}

Miracidia were obtained using stool samples from people infected with Schistosoma mansoni in El-Seraha village in Gezira State. Samples were examined by the locally developed direct thick smear method described by Teesdale and Amin (1976). The positive samples containing eggs were put in normal saline and mixed in a conical flask. The stool sample was sieved in a wire mesh and then filtered. The filtrate was collected into a one-liter conical flask. Warm dechlorinated water was added, and the flask was put under artificial light for about one hour to induce hatching.

\section{Test for toxicity of Randia nilotica on miracidia}

The test was carried out according to the method recommended by WHO (1965). First, a group of ten miracidia, suspended in $0.5 \mathrm{ml}$ distilled water, were transferred to micro-titer plates, each containing one $\mathrm{ml}$ of the extract of a known concentration of 25, 50, 100, 250, and $500 \mathrm{ppm}$ of Randia. nilotica. The miracidia were examined under a dissecting microscope over three hours. Next, ten miracidia were transferred to one $\mathrm{ml}$ of distilled water to serve as a control. The death of miracidia was determined by low motility and by exhibiting granular shape. Each experiment was repeated three times for each concentration, and the average of three results was then 
taken. The time taken to kill all miracidia was observed and recorded.

\section{The procedure for snail infection}

The snail used in this procedure was B. pfeifferi. Each snail was placed in a microtiter plate containing $5 \mathrm{ml}$ of fresh water. Then, 3-5 miracidia were added to each microtiter plate. The snails were exposed to schistosome miracidia under light for 24 hours. Screening for schistosome infection to detect transmission of infection in the snails started 30 days after exposure to miracidia.

\section{Detection of the infection in snails}

Firstly, the snails were washed with dechlorinated tap water 2-3 times to wash out tissue debris. Then, they were put in a beaker containing distilled water $(10 \mathrm{ml} / \mathrm{snail})$. Finally, they were exposed to strong artificial light at 25 ${ }^{\circ} \mathrm{C}$. Shedding of cercariae started after about half an hour under these conditions.

The beaker was held against a light source to detect cercariae. Cercariae of Schistosoma species were identified under the microscope by biforked tails and the absence of eyespots. Based on the procedure mentioned above, the snails were screened, and the infected ones were isolated for use in the experiment. They were then exposed to artificial light for half an hour to produce the cercariae. A volume of $0.5 \mathrm{ml}$ solution containing the cercariae was randomly taken and spread on a petri dish. The cercariae were then fixed, stained with lougols iodine, and counted under a dissecting microscope. The required number for the test was then taken from the sample.

\section{Cercaricidal activity test}

The test was carried out according to the method recommended by WHO (1965). Twenty cercariae were suspended in $0.1 \mathrm{ml}$ distilled water and incubated with one $\mathrm{ml}$ of different concentrations of the plant $R$. nilotica extract in micro-titer plates. The concentrations used were $25,50,100,250$, and 500ppm. The micro-titer plates were examined under a microscope for over five hours after the activity decreased. The time required to kill all cercariae was recorded. Cercariae were considered dead if they became immotile and/or their oral and ventral suckers were extended. Twenty cercariae were transferred to one $\mathrm{ml}$ of distilled water on the same plate to serve as acontrol.

\section{Statistical analysis}

ANOVA, t-test, and probit procedure were carried out to analyze. ANOVA test was used to assess the activity of filtered and unfiltered extracts of the plant $R$. nilotica on $B$. pfeifferi, $B$. truncatus, and cercariae and miracidia of $S$. mansoni using the SPSS program. The correlation coefficient that shows the relationship between the plant concentrations and the effect of this plant on the snails and cercariae and miracidia of $S$. mansoni was calculated. It was then drawn into a graph for filtered and unfiltered extracts against $B$. pfeifferi, B. truncatus, and cercariae and miracidia of Schistosoma mansoni. The potencies of filtered and unfiltered extracts on $B$. pfeifferi and $B$. truncatus and the potency of the unfiltered extract on infected and uninfected B. pfeifferi T-test were compared. Furthermore, the probit analysis was used to confirm the potency of $R$. nilotica filtered and unfiltered extract against B. pfeifferi and B. truncatus and to confirm the potency of the unfiltered extract on infected B. pfeifferi by cercaria of S. mansoni. The probit values were calculated using the log values of the concentrations of the extract and the percentage of mortalities corresponding to them.

$\mathrm{Y}_{1}=(\mathrm{Y}-\mathrm{bx})+\mathrm{bx} 1$

Where

(Y1) is the calculated (predictable) probit value.

$(\mathrm{Y})=$ average of the $\%$ mortalities.

$(\mathrm{X})=$ average of the extract concentrations. $\mathrm{b}=$ is $\mathrm{a}$ constant (least square estimate).

$\mathrm{X}=$ is the $\log$ of the concentration used.

\section{RESULTS AND DISCUSSION}

\section{The activity of Randia nilotica filtered and unfiltered extract on Biomphalaria pfeifferi}

The titration of the activity of filtered extract on $B$. pfeifferi revealed that at $20 \mathrm{ppm}$ resulted in $3 \%$. In contrast, at $30 \mathrm{ppm}$ produced $13 \%$ mortality, at $40 \mathrm{ppm}$ resulted in $23 \%$ mortality, at $50 \mathrm{ppm}$ resulted in $36 \%$ mortality, at 60 ppm resulted in $46 \%$, concentration of 70 ppm produced $70 \%$ mortality, at $80 \mathrm{ppm}$ produced $83 \%$ mortality, at 90 ppm resulted in $93 \%$ mortality. Finally, the highest concentration of $100 \mathrm{ppm}$ produced $100 \%$ mortality (Figure 1).

On the other side, the activity of unfiltered extract on the snails showed that at $20 \mathrm{ppm}$ resulted in $6 \%$. In comparison, at $30 \mathrm{ppm}$ produced $16 \%$ mortality, at $40 \mathrm{ppm}$ resulted in $30 \%$ mortality, at $50 \mathrm{ppm}$ resulted in $53 \%$ mortality, at $60 \mathrm{ppm}$ resulted in $70 \%$, at $70 \mathrm{ppm}$ produced $83 \%$ mortality, at $80 \mathrm{ppm}$ produced $90 \%$ mortality. In comparison, a concentration of $90 \mathrm{ppm}$ resulted in $100 \%$ mortality (Figure 2).

The effect of the filtered extract on the snail was highly significant $(p \leq 0.001)$ (Table 1$)$. At the same time, the correlation was positive between the filtered extract concentrations and the mortality; the correlation was positive $(\mathrm{r}=0.960)$, and it was highly significant $(\mathrm{p} \leq 0.01)$. The effect of the other unfiltered extract was also highly significant $(p \leq 0.001$, Table 1$)$, and the correlation was positive $(r=0.969)$ and highly significant $(\mathrm{p} \leq 0.01)$.

There was no significant difference in potency of the filtered and unfiltered extract on $B$. pfeifferi. In the concentrations of $10 \mathrm{ppm}$ and $100 \mathrm{ppm}$, there were no significant differences ( $\mathrm{p}=--)$. In comparison, a difference was found at $20 \mathrm{ppm}(\mathrm{p}=1.000)$, and at $30 \mathrm{ppm}$, no significant difference was recorded between filtered and unfiltered extract $(\mathrm{p}=0.519)$. At $40 \mathrm{ppm}$, the result showed no significant differences $(\mathrm{p}=0.491)$. In the concentrations of $50 \mathrm{ppm}$ and at $60 \mathrm{ppm}$ the results were recorded as $(\mathrm{p}=$ $0.152)$ and as $(p=0.091)$, respectively. In concentration of $70 \mathrm{ppm}(\mathrm{p}=0.411)$, in concentration of $80 \mathrm{ppm}(\mathrm{p}=$ 
0.492), and in concentration of $90 \mathrm{ppm}$ no significant difference was shown $(\mathrm{p}=0.116)$ (Figure 3)

\section{The activity of Randia nilotica filtered and unfiltered extract on Bulinus truncatus}

The titration of the activity of filtered extract revealed that concentration of $20 \mathrm{ppm}$ resulted in $6 \%$. In comparison, at $30 \mathrm{ppm}$ produced $13 \%$ mortality, at $40 \mathrm{ppm}$ resulted in $30 \%$ mortality, and at $50 \mathrm{ppm}$ resulted in $52 \%$ mortality. In comparison, at $60 \mathrm{ppm}$ resulted in $70 \%$, a concentration of $70 \mathrm{ppm}$ produced $83 \%$ mortality, at 80 ppm produced $91 \%$ mortality, and at $90 \mathrm{ppm}$ resulted in $100 \%$ mortality (Figure 4). On the other side, the activity of unfiltered extract on the snail showed that at $20 \mathrm{ppm}$ resulted in $7 \%$. In comparison, at $30 \mathrm{ppm}$ produced $23 \%$ mortality, at $40 \mathrm{ppm}$ resulted in $41 \%$ mortality, and at $50 \mathrm{ppm}$ resulted in $70 \%$ mortality. In comparison, at 60 ppm resulted in $86 \%$, at $70 \mathrm{ppm}$ produced $93 \%$ mortality, while at $80 \mathrm{ppm}$ produced $100 \%$ mortality (Figure 5).

The effect of the filtered extract on B. truncatus was highly significant $(\mathrm{p} \leq 0.001$, Table 1$)$. The correlation coefficient was positive $(r=0.966)$ and was highly significant $(\mathrm{p} \leq 0.01)$. The effect of the unfiltered extract on B. truncatus was also highly significant $(\mathrm{p} \leq 0.001)$ (Table 1). In addition, the correlation between extract concentration and the percentage mortality was positive ( $r$ $=0.945)$ and was highly significant $(\mathrm{p} \leq 0.01)$.

The concentration of $10 \mathrm{ppm}$ was not significant $(\mathrm{p}=-)$, and the same result was produced in concentrations of 90 ppm and $100 \mathrm{ppm}$. In concentration of $20 \mathrm{ppm}$ the significance was $(\mathrm{p}=1.000)$, while in concentration of 30 $\mathrm{ppm}$, it was $(\mathrm{p}=0.230)$, the significance in concentration of $40 \mathrm{ppm}$ was $(\mathrm{p}=0.288)$, in concentrations 50 of ppm and $60 \mathrm{ppm}$ the effect showed no significance $(\mathrm{p}=0.189)$ and $(\mathrm{p}=0.067)$, respectively. At $70 \mathrm{ppm}$, the significance was $(\mathrm{p}=0.101)$, while at the final concentration of $80 \mathrm{ppm}$, the significance was $(\mathrm{p}=0.158)$ (Figure 6$)$.

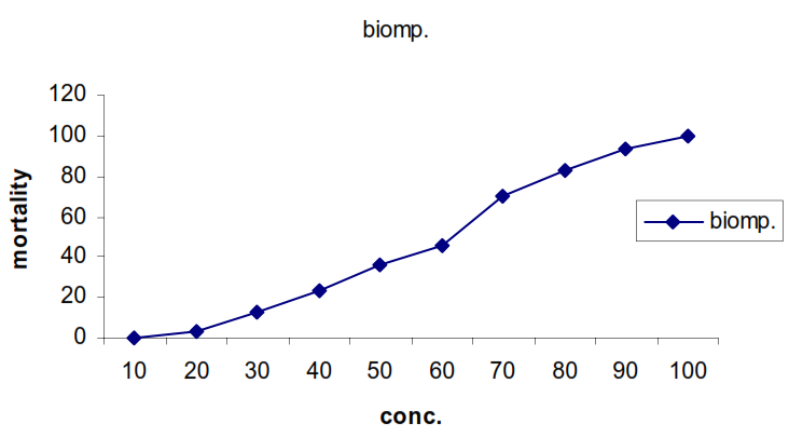

Figure 1. The effect of $R$. nilotica filtered extract concentration on Biomphalaria pfeifferi. Correlation Coefficient $=0.960$

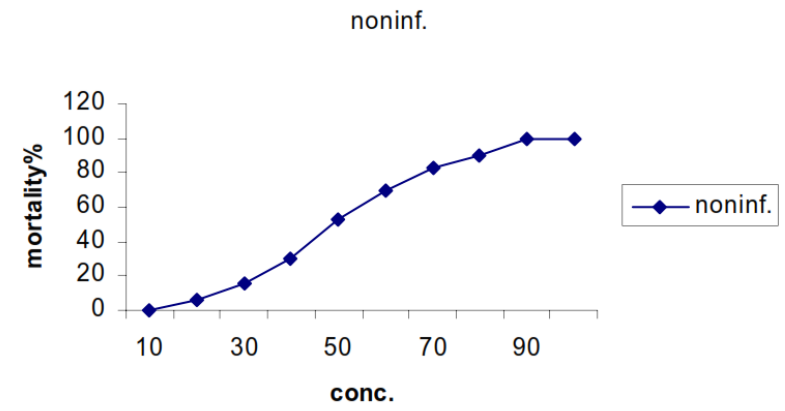

Figure 2. The effect of $R$. nilotica unfiltered extract concentration on Biomphalaria pfeifferi . Correlation Coefficient $=0.969$

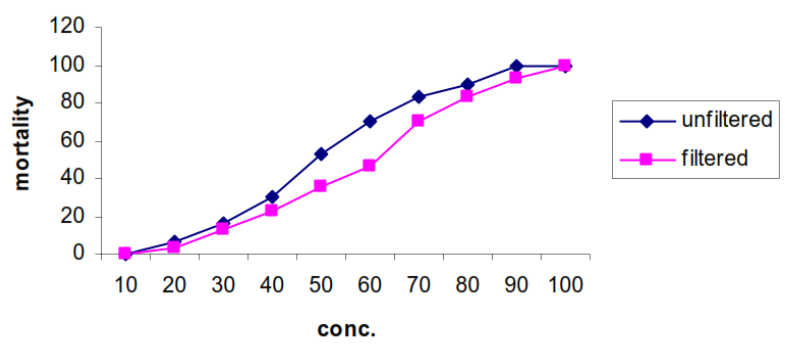

Figure 3. The effect of $R$. nilotica filtered and unfiltered extract on Biomphalaria pfeifferi.



Figure 4. The effect of $R$. nilotica filtered extract concentration on Bulinus truncatus. Correlation Coefficient $=0.966$



Figure 5. The effect of $R$. nilotica unfiltered extract concentration on Bulinus truncatus. Correlation Coefficient $=0.945$ 
The activity of Randia nilotica unfiltered extract on infected and uninfected Biomphalaria pfeifferi

The titration of the activity of unfiltered extract of $R$. nilotica on infected $B$. pfeifferi revealed that a concentration of $20 \mathrm{ppm}$ resulted in $3 \%$ while at $30 \mathrm{ppm}$ produced $23 \%$ mortality, at $40 \mathrm{ppm}$ resulted in $33 \%$ mortality, at $50 \mathrm{ppm}$ resulted in $70 \%$ mortality, at $60 \mathrm{ppm}$ resulted in $90 \%$ mortality, at $70 \mathrm{ppm}$ produced $100 \%$ mortality (Figure 7 ).

The effect of the unfiltered extract on infected $B$. pfeifferi snail was highly significant $(\mathrm{p} \leq 0.001)$ (Table 1$)$. Moreover, it gave a positive correlation. The correlation coefficient was $(\mathrm{r}=0.934)$; this correlation was highly significant $(\mathrm{p} \leq 0.01)$.

There were no significant differences in potency of the unfiltered extract on infected and uninfected Biomphalaria snails; in a concentration of $10 \mathrm{ppm}$, there were no significant differences ( $p=--)$. The same result was produced in concentrations of $90 \mathrm{ppm}$ and $100 \mathrm{ppm}$. There was no significant difference in concentration of $20 \mathrm{ppm}$ ( $\mathrm{p}$ $=0.519)$, while in concentration of $30 \mathrm{ppm}$ the significance was $(\mathrm{p}=0.230)$, in concentrations of $40 \mathrm{ppm}$ and $50 \mathrm{ppm}$ there was no significant difference $(\mathrm{p}=0.725)$ and $(\mathrm{p}=$ 0.189 ), respectively. In concentration of $60 \mathrm{ppm}$ gave no significance $(\mathrm{p}=0.070)$. the significance in concentration of 70 ppm was $(\mathrm{p}=0.132)$, while in concentration of 80 ppm was $(\mathrm{p}=0.158)$ (Figure 8).

\section{The activity of Randia nilotica filtered extract on cercariae of Schistosoma mansoni}

The activity of $R$. nilotica filtered extract on cercariae showed that at $500 \mathrm{ppm}$ killed all cercariae in a few minutes (15 minutes), and at 250 killed the cercariae at 30 minutes. At $50 \mathrm{ppm}$, the cercariae were killed in about 3 hours, while at $25 \mathrm{ppm}$ did not affect cercariae for about five hours ( Figure 9).

The effect of the plant on cercariae was highly significant $(p \leq 0.001)$ (Table 1). Furthermore, the time to kill the cercariae was decreased when the used concentration increased; this means the correlation was negative, the correlation coefficient was $(r=-0.751)$, and this correlation was highly significant $(\mathrm{p} \leq 0.01)$.

\section{The activity of Randia nilotica filtered extract on miracidia of Schistosoma mansoni}

The activity of $R$. nilotica filtered extract on miracidia showed that at $500 \mathrm{ppm}$ killed the miracidia just in 10 minutes, and the concentrations of $250 \mathrm{ppm}$ and $100 \mathrm{ppm}$ killed all miracidia in 20 minutes and 45 minutes, respectively. While at $50 \mathrm{ppm}$ killed all miracidia in 2 hours, at $25 \mathrm{ppm}$ produced no effect on miracidia for up to 3 hours (Figure 9).

The plant was very effective on the miracidia of $S$. mansoni and was highly significant $(\mathrm{p} \leq 0.001)$ (Table 1$)$. Although it was a negative correlation, the correlation coefficient $(r=-0.773)$ was highly significant $(p \leq 0.01)$.

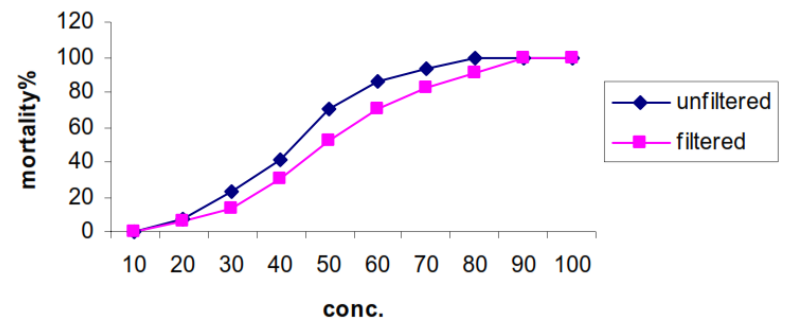

Figure 6. The effect of filtered and unfiltered extract of $R$. nilotica on Bulinus truncatus.

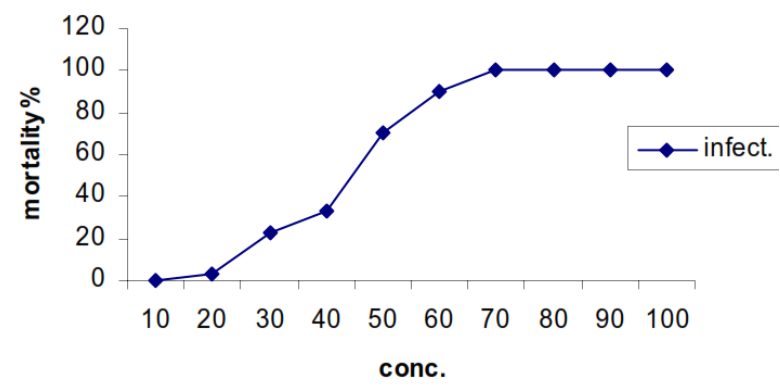

Figure 7. The effect of unfiltered extract of $R$. nilotica on infected Biomphalaria pfeifferi. Correlation Coefficient $=0.934$

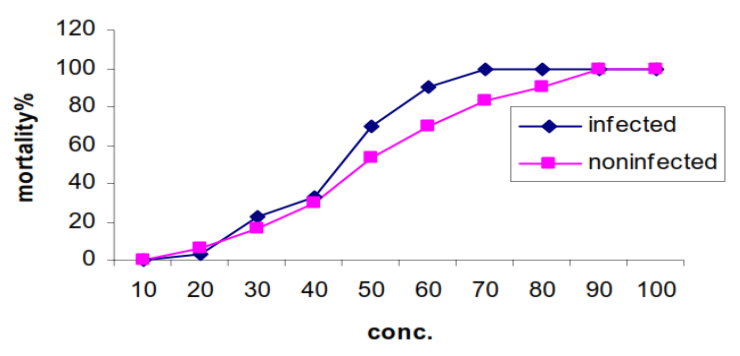

Figure 8. The effect of unfiltered extract of $R$. nilotica on infected and uninfected Biomphalaria pfeifferi

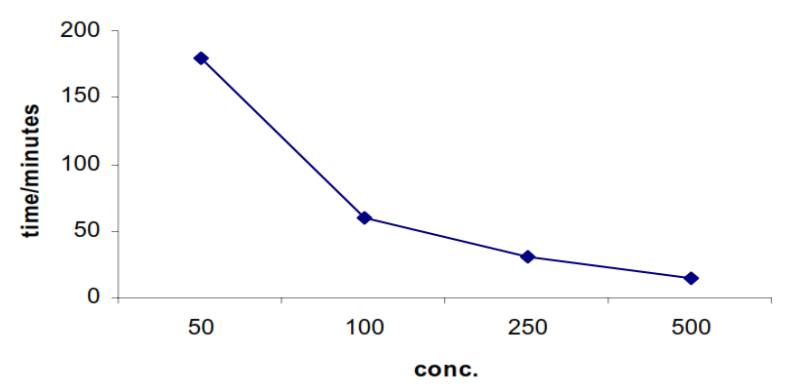

Figure 9. The effect of filtered extract concentration on Cercariae of $S$. mansoni. Correlation Coefficient $=-0.751$ 
Table 1. ANOVA degree of freedom (df), mean squares (MS), R-square (R), and F value (F) for infected and uninfected Biomphalaria, Bulinus, cercariae, and miracidia treated by filtered and unfiltered extract of Randia nilotica

\begin{tabular}{lllllc}
\hline Extract & Source & df & MS & R & F \\
\hline Filtered extract & Biomphalaria pfeifferi & 9 & 42.404 & 0.922 & $34.381^{* * *}$ \\
& Bulinus truncatus & 9 & 46.756 & 0.932 & $63.758^{* * *}$ \\
& Cercariae & 3 & 16818.750 & 0.564 & $1770.395^{* * *}$ \\
& Miracidia & 3 & 7418.750 & 0.598 & $471.032^{* * *}$ \\
& & & & & \\
Unfiltered extract & & & & \\
& (Infected Biomphalaria pfeifferi) & 9 & 54.089 & 0.873 & $135.222^{* * *}$ \\
& (Uninfected Biomphalaria pfeifferi) & 9 & 45.870 & 0.910 & $72.427^{* * *}$ \\
& Bulinus truncatus & 9 & 49.570 & 0.893 & $114.393^{* * *}$ \\
\hline
\end{tabular}

Note: $* * * \mathrm{P} \leq 0.001$

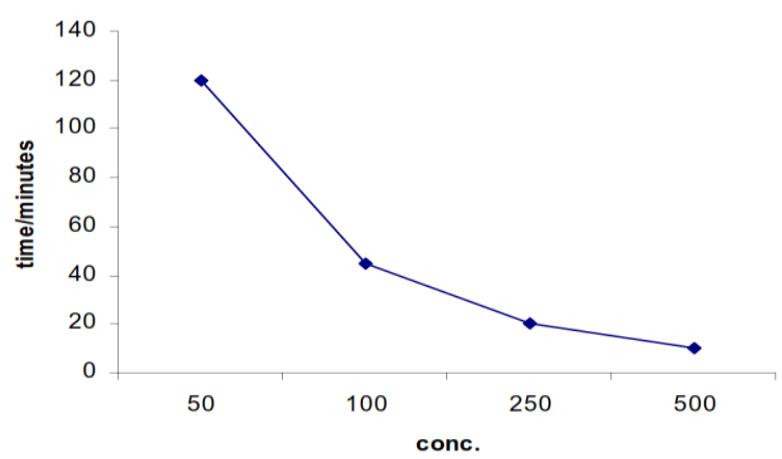

Figure 10. The effect of $R$. nilotica filtered extract concentration on Miracidia of S. mansoni. Correlation Coefficient $=-0.773$

\section{Discussion}

Aqueous extract of the plant $R$. nilotica filtered and unfiltered extract has been used in this study to assess their activities. Filtered and unfiltered extracts were used on the snails B. pfeifferi and B. truncatus, while filtered extract was used against cercariae and miracidia of Schistosoma mansoni. Some researchers have reported high molluscicidal activities in the alcoholic extracts of different parts of several species belonging to the family Rubiaceae (Adewenmi 1980; Ahmed et al. 1994). One of these plants was $R$. nilotica. The stem of this plant was found very active against both snails.

This study revealed that the plant extract was highly effective against $B$. pfeifferi. The filtered extract produced LD50 (probit 5.00) at $53.33 \mathrm{ppm}$ and LD90 (probit 6.28) at $97.95 \mathrm{ppm}$, while $100 \%$ mortality (probit 7.33) was produced at $100 \mathrm{ppm}$. On the other side, the unfiltered extract produced LD50 and LD90 at the concentrations of $46.24 \mathrm{ppm}$ and $85.31 \mathrm{ppm}$, respectively. In comparison, $100 \%$ mortality was produced at $90 \mathrm{ppm}$ and $100 \mathrm{ppm}$. That means unfiltered extract was more potent than filtered one; that effect may be due to the debris on an unfiltered extract that snails fed. At the same time, at 10 ppm, there was no effect on filtered and unfiltered extracts.
The effect of the two extracts revealed no significant differences in each concentration.

R. nilotica on B. truncatus revealed that filtered extract produced LD50 at $46.56 \mathrm{ppm}$. In comparison, it produced LD90 when the concentration increased to $84.33 \mathrm{ppm}$, indicating that $100 \%$ mortality was reached when $90 \mathrm{ppm}$ and $100 \mathrm{ppm}$ were used. On the other hand, the effect of the unfiltered extract on B. truncatus revealed that LD 50 (probit 5.00) was $39.63 \mathrm{ppm}$, while LD90 (probit 6.28) was produced at $67.61 \mathrm{ppm}$. In comparison, $100 \%$ mortality was produced when the concentrations $80 \mathrm{ppm}, 90 \mathrm{ppm}$, and $100 \mathrm{ppm}$ were used.

\section{The effect of each concentration revealed no significant difference between filtered and unfiltered extract on Bulinus truncatus.}

The above results indicate that unfiltered extracts of $R$. nilotica were more potent than filtered ones on both $B$. pfeifferi and B. truncatus. However, high molluscicidal activities were attained on both snails only when higher concentrations were used, i.e., $100 \%$ resulted in concentrations of $100 \mathrm{ppm}$, and $90 \mathrm{ppm}$ of filtered extract and $90 \mathrm{ppm}$ and $80 \mathrm{ppm}$ of the unfiltered extract on $B$. pfeifferi and Bulinus truncates, respectively.

The concentrations of filtered extract were relatively low compared to the stem extracts of $R$. nilotica, which produced $100 \%$ mortality when $1150 \mathrm{ppm}$ and $1000 \mathrm{ppm}$ were used on B. pfeifferi and B. truncatus, respectively (Ibrahim 1998). The results also revealed that the snail $B$. pfeifferi was more resistant than $B$. truncatus in both extracts. However, $100 \%$ mortality was attained when 100 ppm and $90 \mathrm{ppm}$ were used on B. pfeifferi and $90 \mathrm{ppm}$ and $80 \mathrm{ppm}$ on B. truncatus of filtered and unfiltered extracts, respectively.

The plant was also used against infected B. pfeifferi by miracidia of $S$. mansoni; the unfiltered extract was highly effective, LD50 with $40.83 \mathrm{ppm}$, while $90 \%$ mortality was produced at $65.16 \mathrm{ppm}$. The concentrations that produced $100 \%$ mortality were $70 \mathrm{ppm}, 80 \mathrm{ppm}, 90 \mathrm{ppm}$, and 100 ppm. 
Table 9. Means $( \pm \mathrm{SE})$ of the effect of Randia nilotica filtered and unfiltered extract on infected Biomphalaria pfeifferi uninfected $B$. pfeifferi and Bulinus truncatus

\begin{tabular}{|c|c|c|c|c|c|}
\hline \multirow[b]{2}{*}{$\begin{array}{l}\text { Extract conc. } \\
\quad(p p m)\end{array}$} & \multicolumn{4}{|c|}{ Uninfected } & \multirow[b]{2}{*}{$\begin{array}{c}\text { Infected } B . \\
\text { pfeifferi }\end{array}$} \\
\hline & $\begin{array}{c}\text { Filtered on } B . \\
\text { pfeifferi }\end{array}$ & $\begin{array}{c}\text { Filtered on } B . \\
\text { truncatus }\end{array}$ & $\begin{array}{c}\text { Unfiltered on } B . \\
\text { pfeifferi }\end{array}$ & $\begin{array}{c}\text { Unfiltered on } B . \\
\text { truncatus }\end{array}$ & \\
\hline 10 & $0.00 \pm 0.00$ & $0.00 \pm 0.00$ & $0.00 \pm 0.00$ & $0.00 \pm 0.00$ & $0.00 \pm 0.00$ \\
\hline 20 & $0.33 \pm 0.30$ & $0.67 \pm 0.33$ & $0.67 \pm 0.30$ & $0.67 \pm 0.60$ & $0.33 \pm 0.30$ \\
\hline 30 & $1.33 \pm 0.33$ & $1.33 \pm 0.67$ & $1.67 \pm 0.33$ & $2.33 \pm 0.33$ & $2.33 \pm 0.33$ \\
\hline 40 & $2.33 \pm 0.67$ & $3.00 \pm 0.58$ & $3.00 \pm 0.58$ & $4.00 \pm 0.58$ & $3.33 \pm 0.67$ \\
\hline 50 & $3.67 \pm 0.80$ & $5.33 \pm 0.88$ & $5.33 \pm 0.33$ & $7.00 \pm 0.58$ & $7.00 \pm 0.58$ \\
\hline 60 & $4.67 \pm 0.88$ & $7.00 \pm 0.58$ & $7.00 \pm 0.58$ & $8.67 \pm 0.33$ & $9.00 \pm 0.50$ \\
\hline 70 & $7.00 \pm 1.15$ & $8.33 \pm 0.33$ & $8.33 \pm 0.88$ & $9.33 \pm 0.33$ & $10.00 \pm 0.00$ \\
\hline 80 & $8.33 \pm 0.67$ & $9.00 \pm 0.58$ & $9.00 \pm 0.58$ & $10.00 \pm 0.00$ & $10.00 \pm 0.00$ \\
\hline 90 & $9.33 \pm 0.33$ & $10.00 \pm 0.00$ & $10.00 \pm 0.00$ & $10.00 \pm 0.00$ & $10.00 \pm 0.00$ \\
\hline 100 & $10.00 \pm 0.00$ & $10.00 \pm 0.00$ & $10.00 \pm 0.00$ & $10.00 \pm 0.00$ & $10.00 \pm 0.00$ \\
\hline
\end{tabular}

Table 10. Means $( \pm \mathrm{SE})$ of the effect of time (minutes) of mortality of Miracidia and Cercariae due to the effect of Randia nilotica filtered extract.

\begin{tabular}{lcc}
\hline $\begin{array}{l}\text { Extract conc. } \\
(\mathbf{p p m})\end{array}$ & Miracidia & Cercariae \\
\hline 50 & $120 \pm 2.89$ & $180 \pm 2.89$ \\
100 & $45 \pm 2.89$ & $60 \pm 1.53$ \\
250 & $20 \pm 1.73$ & $30 \pm 1.00$ \\
500 & $10 \pm 1.15$ & $15 \pm 1.00$ \\
\hline
\end{tabular}

These results revealed that uninfected snail was more resistant than the infected one; $100 \%$ mortality was given at $90 \mathrm{ppm}$ on uninfected snails and $70 \mathrm{ppm}$ on infected ones (Table 2). This difference may be due to the morbidity of infected snails by miracidia. The effect of unfiltered extract of the plant revealed no significant difference between infected and uninfected $B$. pfeifferi.

The activity of the plant on the miracidia of S. mansoni was observed in the time taken to kill all miracidia. In concentrations of $50 \mathrm{ppm}$ and $100 \mathrm{ppm}$, miracidia were killed in about 120 minutes and 45 minutes, respectively. The concentration of $250 \mathrm{ppm}$ killed miracidia in about 20 minutes, while at $500 \mathrm{ppm}$ killed all miracidia in a fewer time (10 minutes) (Tabel 3).

The effect of the plant on the miracidia of S. mansoni was highly significant.

The plant was used against the cercariae of $S$. mansoni; at $50 \mathrm{ppm}$ killed the cercariae within 180 minutes. The concentration of $100 \mathrm{ppm}$ killed the cercariae within 60 minutes, while concentrations of $250 \mathrm{ppm}$ and $500 \mathrm{ppm}$ killed all cercariae within 30 minutes and 15 minutes, respectively (Table 2). The effect of the plant was highly significant when used against the cercariae of $S$. mansoni.

These results revealed that cercariae were more resistant than miracidia. These results were attained when only a lower concentration was used, i.e., at $50 \mathrm{ppm}$, the time taken to kill cercariae and miracidia was 180 minutes and 120 minutes, respectively. It was observed that at 25 ppm was not active on both miracidia and cercariae within 3 hours and 5 hours, respectively (Tabel 3).
Forty Sudanese plants were tested by El-Shiekh (1994) for their miracidicidal and cercaricidal activity against $S$. mansoni. In these plants, $R$. nilotica was found highly effective by killing all miracidia and cercariae of $S$. mansoni at $50 \mathrm{ppm}$ within 3 hours and 5 hours, respectively. However, the correlation coefficient (r) was negative. That means that when at the plant extract was increased, the time taken to kill all cercariae and/or miracidia decreased.

Bashir et al. (1987) reported the activity of the plant Acacia nilotica, with subspecies nilotica and adansoni against cercariae and miracidia of S. mansoni. They found that high concentrations of both plant subspecies killed both cercariae and miracidia, as a concentration of 5,000 ppm of A.nilotica with subspecies nilotica killed cercariae and miracidia within 80 minutes and 35 minutes, respectively. Similar concentrations in the other subspecies (adansoni) killed cercariae and miracidia within 100 minutes and 80 minutes, respectively. Al-Sayed et al. 2014) reported that Eucalyptus globulus has a potential source for biocidal compounds against $S$. mansoni and its snail host. Ibrahim et al. 2015) stated that Agave angustifolia and Pittosporum tobira have cercaricidal and miracidicidal potencies against $S$. mansoni.

Ibrahim (1998) tested the potency of the stem of the plant Randia nilotica on B. pfeifferi and B. truncates, and showed the activity of the plant against cercariae and miracidia of $S$. mansoni. The plant killed the snails at high concentrations, with $100 \%$ mortality reached when concentrations of 1,200 ppm and 1,300 ppm were used on B. pfeifferi and B. truncatus, respectively. On the other hand, the $100 \%$ mortality of cercariae and miracidia of S. mansoni was taken in concentrations of $100 \mathrm{ppm}$ and 50 ppm, respectively. These differences may be due to the plant's part (s) used, and the plant used in that study was obtained from Sudan National Garden in Khartoum, where this plant was cultivated.

In conclusion, from molluscicidal examinations of the plant $R$. nilotica against $B$. pfeifferi and $B$. truncatus, it could be concluded that the activity of this plant was high in the form of both filtered and unfiltered extract against both snails, and it gave good results even in lower 
concentrations. All experiments also showed that at $10 \mathrm{ppm}$ did not produce any activity against the snails. Furthermore, the cercaricidal and miracidicidal activity of the plant revealed that it was very effective on the cercariae and miracidia of $S$. mansoni as it gave $100 \%$ mortality in a short time at lower concentrations. Also, in these experiments, at $25 \mathrm{ppm}$ did not give any activity on the cercariae and/or miracidia of $S$. mansoni. Therefore, based on the results of the present study, it seems reasonable to conclude that the plant can be used to control schistosomiasis in Sudan, as it has numerous molluscicidal, cercaricidal, and miracidicidal activities. In addition, the plant grows naturally in different parts of Sudan, and its application requires simple technology.

\section{REFERENCES}

Adewenmi CO. 1980. Water extract of tetra pleura: An effective molluscicide for the control of Schistosomiasis and Fascioliasis in Nigeria. J Anim Prod 3: 7-15.

Ahmed MM, Hady, HM, Salama, MM, EL-Ghazali, S. 1994. Laboratory study on the molluscicidal effect of Earth Tec: an environmentally responsible copper sulfate product. J Egypt Soc Parasitol 24: 317-322.

Al-Sayed E, Hamid HA, Abu El Einin HM. 2014. Molluscicidal and antischistosomal activities of methanol extracts and isolated compounds from Eucalyptus globulus and Melaleuca styphelioides. Pharm Biol 52 (6):698-705.

Basch PF. 1991. Schistosomes. Development, Reproduction and Host Relations. Oxford University press, New York.

Bashir AK, Sulaiman SM, EL-Sheikh SH, EL-Kheir YM. 1987. Molluscicidal, Cercaricidal and Miracidicidal activity of Acacia nilotica SSP. nilotica and adansoni. Fitoterapia 108: 51-55.

Brackenbury TD. 1999. The molluscicidal properties of Apodytes dimidiata (Icacinaceae): geographical variation in molluscicidal potency. Ann Trop Med Parasitol 93 (5):511-518.

Brackenbury TD, Apleton CC, Kayonga L, Drewes SE. 1997. Molluscicidal properties of Apodytes dimidiata (Icacinaceae): Geographic variation in molluscicidal potency. J Med Appl Malacol 14: 299-302.

Brown DS. 1994. Fresh water snails of Africa and their medical importance. Taylor and Francis Ltd, London.

Doumenge JP, Mott KE, Cheung C, Villenava D, Chapuis O, Perrin MF, Reuad-Thomas G. 1987. Atlas of the global distribution of Schistosomiasis. Press Universitaires de Bordeaux, Talence.
El-Sheikh SH. 1994. Biological and Chemical Studies on Molluscicidal and Schistosomicidal Compounds. [Dissertation]. Faculty of Science, University of Khartoum, Khartoum.

Hotez PJ, Fenwick A. 2009. Schistosomiasis in Africa: An emerging tragedy in our new global health decade. PLoS Negl Trop Dis 3 (9): e485. DOI: 10.1371/journal.pntd.0000485

Hotez PJ, Kamath A. 2009. Neglected tropical diseases in sub-Saharan Africa: review of their prevalence, distribution, and disease burden. PLoS Negl Trop Dis. 3: e412. DOI: 10.1371/journal.pntd.0000412.

Hussein MF. 1973. Animal schistosomiasis in Africa, A review of Schistosoma bovis and Schistosoma matteei. Veterinary Bulletin 43: 341-347.

Ibrahim AM, Abdel-Gawad MM, El-Nahas HA, Osman NS. 2015. Studies on the molluscicidal activity of Agave angustifolia and Pittosporum tobira on schistosomiasis transmitting snails. J Egypt Soc Parasitol. 45 (1):133-41.

Ibrahim AB. 1998. The molluscicidal activity of Catunaregam nilotica and Vangueria venosa. [Thesis]. Faculty of Veterinary Medicine, University of Khartoum, Khartoum.

Inobaya MT, Olveda RM, Chau TNP, Olveda DU, Ross AGP. 2014. Prevention and control of schistosomiasis: a current perspective. Res Rep Trop Med 17 (5): 65-75.

Jordan P, Webbe G, Sturrock RF. 1993. Human Schistosomiasis, CAB International, Wallingford, UK.

Korte R, Mott K.E. 1980. Maintenance of Schistosomiasis control-an overview. Trop Med Parasitol 40: 130-131.

Lai YS, Biedermann P, Ekpo UF, et al. 2015. Spatial distribution of schistosomiasis and treatment needs in sub-Saharan Africa: a systematic review and geostatistical analysis. Infec Dis 15 (8): 927 940.

McCullough FS, Mott KE. 1983. The role of molluscicides in schistosomiasis control. WHO document. WHO/SHISTO/83.72.

Steinmann P, Keiser J, Bos R, Tanner M, Utzinger J. 2006. Schistosomiasis and water resources development: systematic review, meta-analysis, and estimates of people at risk. Lancet Infect Dis 6: 411-425.

Sulaiman SM, Ibrahim SM. 1985. Schistosoma mansoni (Gezira) infection in Biomphalaria pfeifferi snails from Gezira and Jebel Marra. J Trop Med Hyg 88:91-93.

Teesdale CH, Amin MA. 1976. Comparison of the bell technique, a modified kato thick smear technique and the digestion method for the field diagnosis of Schistosoma mansoni. J Helminthol 50: 17-20.

Wains GJP, McManus DP. 1997. Schistosomiasis vaccine development. The current picture. Bioassay. 19: 435-443.

WHO. 1965. Molluscicides screening and evaluation. Bulletin of the World Health Organization 33: 567-581.

WHO. 1973. Schistosomiasis control. WHO Expert Committee on Schistosomiasis. World Health Organization: technical Report. Series No. 515: 47.

WHO. 1994. The Control of Schistosomiasis. WHO Tech. Rep. Ser. 830 